Dr. Charles A. Browne, of the Bureau of Agricultural and Industrial Chemistry, U.S. Department of Agriculture, on "Thomas Jefferson and the Scientific Trends of his Time". The famous statesman-scientist -a type not unknown among the countrymen of Franklin, Rumford, and Hoover, and all too rare elsewhere-was, it appears, not greatly attracted by theory and speculation, which, indeed, he occasionally condemned in severe terms; his scientific interests were largely utilitarian, as is evidenced by many passages from his voluminous correspondence; and his outlook thus admirably fitted him to play the part of scientific scout for America during his residence in Paris as Minister to France (1784-89).

It is interesting to note that during these years in Paris, though he was an eye-witness of the chemical revolution effected by Lavoisier, he was sceptical about the new system of chemical nomenclature. Writing to Madison on this matter on July 19, 1788, he concluded : "The attempt, therefore, of Lavoisier to reform the chemical nomenclature, is premature. One single experiment may destroy the whole filiation of his terms, and his string of sulphates, sulphites, and sulphures, may have served no other end, than to have retarded the progress of the science, by a jargon, from the confusion of which, time will be requisite to extricate us. Accordingly. it is not likely to be admitted generally."

Jefferson's "Notes on the State of Virginia", his magnificent labours in bringing science to the service of the young and undeveloped country in the guidance of the destinies of which he was ultimately called to the highest place, his devoted work for agriculture, and his outstanding services to the cause of science in education, are all well summarized in this interesting memoir.

\section{Stars with Large Proper Motions}

A. VAN MaANEN has prepared a paper with this title (Astro. Soc. Pacific, Leaf. $176 ; 1943$ ) which deals with the developments in the discoveries of stellar motions, from the time of Tobias Mayer who determined the motions of several stars in 1760 , by comparing his own observations with those of Römer made fifty years earlier. A useful table gives the proper motions of thirty stars with the largest proper motions, in all cases exceeding $3^{\prime \prime}$ annually. Large proper motion suggests relative proximity to the earth, and for this reason it is not surprising that nineteen of the thirty stars are less than 16.3 lightyears distant from the sun, and seven are nearer than $32 \cdot 6$ light-years. A very interesting feature in the table is the luminosity of each star, that of the sun being the unit. Only one star-w Centauri $A-$ is brighter than the sun, its luminosity being $1 \cdot 14$. The table also shows that stars with the faintest luminosities belong to the most advanced spectral types and so have the lowest temperatures, with the exception of the white dwarfs. The luminosities of the latter are very low, that of Wolf 489 being only $0 \cdot 00008$.

\section{Electrical Aspect of Farm Mechanisms}

A PAPER on this subject was read in London recently by Mr. C. A. Cameron-Brown before the Institution of Electrical Engineers in which, for the benefit of those interested but not actively engaged in rural electrification, a picture is drawn of the general developments of electrical participation in farm processes ; the paper also offers a clearing house of ideas for those actively engaged in rural electrification but whose interest is localized. The paper is devoted chiefly to the less common applications, to those which are the subject of controversy, and to those which may appear to have a wider field of application in the future. Emphasis has been placed on trend rather than on facts and figures; thus $\mathrm{Mr}$. Cameron-Brown covers general trends and observations, specific applications of electricity to farming operations such as grinding mills, threshing, crop drying, milk production and certain special applica. tions. The scope of the paper is confined to general farming arable, dairy and mixed.

\section{Theodor Puschmann (1844-1899)}

Prof. Theodor PuschmanN, the eminent medical historian, was born on May 4, 1844, at Lowenberg in Prussian Silesia. He studied medicine successively at Berlin, Marburg, Vienna and Munich, and qualified at Marburg in 1869. He first made a study of psychiatry under von Gudden at Munich and then practised for some years in Cairo. In 1878 he specialized in the history of medicine at Leipzig, and in the following year was appointed extraordinary professor of medical history at Vienna, becoming full professor in 1879 in succession to Prof. R. Seligmann. He died on September 28, 1899. His principal publications were an edition of Alexander of Tralles (1878-79), a "History of Medical Education" (1889) and "Medicine in Vienna during the last 100 Years" (1884). $\mathrm{He}$ also wrote the introduction to a great work on the history of medicine which was completed by Prof. Max Neuburger and J. Pagel. His name has been given to a medico-historical institute in Leipzig founded by his wife.

\section{Announcements}

THE twenty-third Silvanus Thompson Memorial Lecture of the British Institute of Radiology will be delivered by Prof. Sidney Russ on May 20; he will speak on "The Man Silvanus Thompson".

A whore-DAY conference of the Nutrition Society will be held on May 20, beginning at 10.50 a.m., at the London School of Hygiene and Tropical Medicine, Keppel Street, W.C.1, on "Budgetary and Dietary Surveys of Families and Individuals, Part 2". Papers will be communicated by Miss E. M. Widdowson and Dr. R. A. MeCance ("Dietary Surveys by the Individual Method"); Dr. Gertrude Wagner ("Surveys of Methods Used in Preparing and Cooking Foods"); Dr. G. N. Jenkins, Dr. L. W. Mapson and Miss M. Olliver "'Laboratory Assessment of Nutritive Value of Meals as Eaten"); Miss E. M. Langley ("Food Consumption: Data Obtained from Analyses of Institutional Diets: (a) School Diets"); Dr. M. Pyke ("Food Consumption: Data Obtained from Analyses of Institutional Diets : (b) Industrial Canteens") ; Dr. A. Lyall ("Food Consumption: Data Obtained from Analyses of Institutional Diets: $(c)$ Hospital Diets"). The openers of the discussion will be Prof. V. H. Mottram, Mrs. Barbara Callow, Dr. C. P. Stewart and Miss M. C. Broatch.

Erratum.-In connexion with the article in NATURE of April 29 on "X-Ray Analysis in Industry", Mr. C. W. Bunn states that the concluding sentence on his paper (p. 534, col. 1) should read "This last effect has been observed in polyethylene, and confirmed by the magnetic properties of single crystals of chain compounds". 